\title{
Evaluation of an application for managing microcredits in education
}

\author{
Susana Munoz-Hernandez \\ Universidad Politecnica de Madrid \\ Computer Science School \\ Montegancedo Campus \\ 28660-Madrid (Spain) \\ susana@fi.upm.es
}

\author{
Maximo Ramirez-Robles \\ Universidad Politecnica de Madrid \\ Computer Science School \\ Montegancedo Campus \\ 28660-Madrid (Spain) \\ mramirez@infomed.dia.fi.upm.es
}

\begin{abstract}
One of the major problems in developing countries is minority access to higher education. Traditional scholarships usually focus on paying eventually tuition fees or bringing brilliant students to develop countries. Additionally, these systems used to be opaque and, consequently, a corruption source. We propose a system of student loans to pay tuition fees in exchange for work. We also provide UBURYO. It is the FOSS, that we have developed, to manage this loan system in a simple, trustworthy, fair and efficient way. We deployed the loan system in the University of Ngozi (UNG, Burundi). A shallow evaluation demonstrates that system sustainability is feasible.
\end{abstract}

\section{General Terms}

Education, Economics, Experimentation

\section{SUMMARY}

Burundi had a per-capita Gross National Income of 160 US\$ in 2010 [1]. It indicates the average income of a country's citizens. On the other hand, the tuition fees for a computer science degree at the UNG were 234 US\$ in 2009. At the time of writing, scholarships are the only approach that is used to redress this imbalance. Institutions help students to pay these fees using donations provided by different organizations or individuals. Another important issue for consideration in developing countries is corruption. Burundi is one

This author is the project supervisor professor.

${ }^{\wedge}$ This author carried out the evaluation in the University of Ngozi. of the world's most corrupt countries [2]. Corruption occurs at all levels, from government down to the actual academic institutions.

We propose a microcredit process in which borrowers repay their loans working for the academic institution. Borrowers may work at the library, paint a wall, fix computers for clients that pay the university, do jobs for a company, etc.. Any member of the university's staff may propose a job. Academic institutions get some kind of benefit from these jobs: savings, profits or added values. Thus, this process allows to set up an economically sustainable cycle in an efficient manner because it offers students professional and practical experiences.

UBURYO is the FOSS to manage this loan process. This software manages the following issues: loan applications, loan allocation, employment bureau and loan repayment. UBURYO allows to monitor a loan since it is allocated until is completely repaid. In addition, every action executed in the system is audited. Therefore, this software forces to the microcredit process to be transparent. All the money charged to the microcredit account will be monitored and every decision made will be stored.

In addition, each delicate decision will be made by an International Committee. E.g., to select the most talented and financially hard-up students from applicants, or, approve jobs proposed by the academic institution's staff. This committee is close enough to the academic institution to know how it works and be acquainted with students and removed enough to enact as fair a process as possible.

The first experiment was carried out at the UNG from October 2009 to October 2010. Different variables were defined and measured and a borrower's opinion poll was conducted. All these data were used to measure sustainability from three totally different points of view: economic sustainability, methodological sustainability and technological sustainability. After one year, the UNG reinvested in the microcredit system a $67 \%$ of the initial funding.

\section{REFERENCES}

[1] W. Bank. Gross national income per capita 2010, atlas method and ppp.

[2] K. Schwab. The global competitiveness report 2009-2010. 